\title{
Evolution of glyphosate resistance in a Lolium rigidum population by glyphosate selection at sublethal doses
}

\author{
R Busi and SB Powles \\ Western Australian Herbicide Resistance Initiative, School of Plant Biology, Faculty of Natural and Agricultural Sciences, \\ The University of Western Australia, Crawley, Western Australia, Australia
}

\begin{abstract}
The majority of the documented cases of field-evolved herbicide-resistant weed biotypes established that single major genes confer glyphosate resistance. However, the contribution of minor genes endowing substantial plant survival at sublethal herbicide doses may be a potential complementary path to herbicide resistance evolution in weed populations under selection. Here, we subjected a number of susceptible individuals of Lolium rigidum to recurrent glyphosate selection to test the potential for sublethal glyphosate doses to additively select for glyphosate resistance. After 3-4 cycles of glyphosate selection in two distinct environments, the progenies of the initially susceptible population were shifted toward glyphosate resistance. The results indicate progressive enrichment of minor gene trait(s) contributing toward plant survival in the glyphosate-selected progenies. After three generations of selection, the estimated $L D_{50}$ values
\end{abstract}

were doubled compared with the original population and up to $33 \%$ plant survival was obtained in the glyphosate-selected progeny at the recommended glyphosate label rate. This level of resistance probably was the maximum shift achievable with sublethal glyphosate dose selection in this small population. Cross-pollination was a crucial factor enabling the rapid rate of accumulation of minor glyphosate resistance gene trait(s) that are likely to be present at a relatively high frequency in a small susceptible population. The mechanistic basis of the moderate glyphosate resistance level selected by sublethal glyphosate doses remains unknown and warrants future research. Studying the main factors influencing the evolution of resistant weed populations is crucial for understanding, predicting and managing herbicide resistance.

Heredity (2009) 103, 318-325; doi:10.1038/hdy.2009.64; published online 3 June 2009

Keywords: recurrent selection; herbicide resistance evolution; glyphosate; VLR1 biotype; small population

\section{Introduction}

Single major gene traits endow resistance in the great majority of documented cases of field-evolved herbicideresistant plants (reviewed by Darmency, 1994). Herbicide selection of large populations of initially herbicidesusceptible plant species selects for the rare individuals expressing resistance genes (reviewed by Jasieniuk et al., 1996). Therefore, it is generally accepted that the dynamics of herbicide resistance evolution are strongly influenced by the initial frequency of major resistance genes in weed populations under herbicide selection (Preston and Powles, 2002). However, a potential concomitant evolutionary path to herbicide resistance in weed populations under selection could be the recurrent enrichment of several additive minor genes, which, in combination, endow sufficient resistance for a substantial number of individuals to survive at the recommended (label) herbicide use rates (Neve and Powles, 2005b). Such enrichment of minor genes would be favored if

Correspondence: Professor S Powles and Roberto Busi, Western Australian Herbicide Resistance Initiative, School of Plant Biology, The University of Western Australia, 35 Stirling Highway, 6009-Crawley, Western Australia, Australia.

E-mails: spowles@plants.uwa.edu.au or rbusi@cyllene.uwa.edu.au Received 3 December 2008; revised 4 May 2009; accepted 11 May 2009; published online 3 June 2009 herbicide selection occurred at a relatively low herbicide dose, such that there would be plant survivors that subsequently produce viable seeds. The rate of herbicide resistance evolution in weed populations subjected to recurrent selection at sublethal doses would rely on additive genetic variation for resistance, the frequency of such minor genes, and the capacity of surviving plants to respond to selection (that is, incremental accumulation toward polygenic resistance) (Holsinger, 2000). In addition, empirical results (Brotherton et al., 2007) and recent modeling simulations of glyphosate resistance evolution (Neve, 2008) suggest the plant reproductive system (cross- vs self-pollination) is a crucial factor in sublethal dose resistance evolution. In cross-pollinated species such as Lolium rigidum Gaud. or Amaranthus palmeri L., gene accumulation or amplification can occur at the individual plant level attributable to herbicide selection after a few generations (Neve and Powles, 2005b; Gaines, 2009).

Although considerable literature exists on the use of sublethal herbicide doses to provide sufficient weed control (reviewed by Zhang et al., 2000; O'Donovan et al., 2007), very few studies have analyzed the subsequent genetic evolutionary consequences of such a low-dose selection (Gressel, 1995). If a herbicide is used at a sublethal dose, then the (low) selection pressure acting within the phenotypic variation is evident in the population and there will likely be survivors. It has been 
suggested that sublethal herbicide doses could enable resistance alleles to be progressively enriched through generations resulting in a polygenic-based shift toward more resistant individuals (Gressel, 2002). Evidence of sublethal drug dose selection for polygenic resistance is known for bacteria (Olofsson and Cars, 2007), fungi (Shaw, 2006) and insects (Roush and McKenzie, 1987). A recent study documented the evolution of resistance in an initially herbicide susceptible $L$. rigidum population subjected to recurrent selection at sublethal herbicide doses for three generations (Neve and Powles, 2005b). The selection and subsequent enrichment of gene traits progressively led to polygenic resistance to diclofopmethyl and concomitant low-level cross-resistance to some other herbicide modes of action. In a separate study, even a single cycle of selection with diclofopmethyl moved susceptible L. rigidum populations (five) toward resistance (Neve and Powles, 2005a). Notwithstanding these results, there is still an ongoing discussion on the effect and relevance of sublethal herbicide doses leading to polygenic herbicide resistance evolution by the accumulation of several minor genes (genes of small effect) vis-à-vis resistance due to a single major gene with a large phenotypic effect (typically a discrete Mendelian gene).

Glyphosate is a potent herbicide that inhibits the enzymatic activity of 5-enolpyruvyl-shikimate-3-phosphate synthase (EPSPS, EC 2.5.1.19) in the shikimate pathway in plants (Duke and Powles, 2008). Since 1996, because of a very high level of adoption of genetically modified glyphosate-resistant crops (that is, 80 million $\mathrm{Ha}$ in 2006 in Argentina, Brazil, Canada and USA), glyphosate has been intensively used across important agricultural regions (reviewed by Dill et al., 2008). In a relatively short period of time, large-scale usage of glyphosate as a principal tool for weed control in glyphosate-resistant crops without diversity has resulted in glyphosate-resistant weeds and shifts in weed communities (reviewed in Owen, 2008; Powles, 2008). Indeed, studies on evolved glyphosate-resistant weeds such as Conyza Canadensis L., Eleusine indica L. and L. rigidum established that single major genes confer glyphosate resistance (Lorraine-Colwill et al., 2001; Ng et al., 2004; Zelaya et al., 2004). However, the contribution of minor genes to additional plant survival at a sublethal dose of glyphosate has also been reported in L. rigidum (Lorraine-Colwill et al., 2001).

L. rigidum is an obligate cross-pollinated species characterized by high genetic diversity (Balfourier et al., 1998). Therefore, even a small L. rigidum population subjected to genetic bottlenecks through recurrent selection can still respond to selection because considerable genetic diversity is retained in the selected progeny (Cooper, 1959; Falconer, 1981). Here, we examined whether a small, glyphosate-susceptible population of L. rigidum could evolve glyphosate resistance when exposed to selection by sublethal doses of glyphosate over consecutive generations.

\section{Materials and methods}

Plant material

This study was conducted with the L. rigidum biotype VLR1, which has never received herbicide selection and is known to be susceptible to all herbicides registered for its control. Seed stocks of this herbicide-susceptible population have been maintained and multiplied since 1985 in the absence of selection and without introgression of any herbicide resistance genes.

\section{Dose-response bioassays and recurrent selection}

Cycles of recurrent selection at sublethal doses of glyphosate were conducted on glyphosate-susceptible population of VLR1 in two separate pot experiments conducted in two different environments (Table 1). In one experiment, plants were grown in plastic pots in a controlled environment room (CER) under fluorescent light $\left(300 \mu \mathrm{mol}\right.$ quanta $\left.\mathrm{m}^{-2} \mathrm{~s}^{-1}\right)$ with a photoperiod of $16 \mathrm{~h}$ at $20 / 12^{\circ} \mathrm{C}$ (light phase coinciding with the warm phase). In a second experiment, plants were grown during the normal growing period (May-August) in a natural outdoor environment simulating field conditions (hereinafter referred to as field). Plants were kept well watered and fertilized. Plants were treated at the twoleaf stage with $0,38,75,150,250,350,450,550$ and $700 \mathrm{gHa}^{-1}$ glyphosate (recommended rate $450 \mathrm{~g} \mathrm{Ha}^{-1}$ ) (RoundUp Power Max as potassium salt, $540 \mathrm{gl}^{-1}$ a.e. SL; Nufarm, Laverton North, VIC, Australia). For each herbicide dose, there were at least three replicates. After 15 days, survivors were counted, and fresh and dry aboveground biomass evaluated. Dose-response bioassays were repeated at least once. Those plants that survived the glyphosate treatment at a certain dose, and grew vigorously after biomass assessment were transplanted and grown to maturity, then confined for crosspollination only with other survivors at that specific dose. The glyphosate selection intensity was based on plant survival ratio at specific sublethal glyphosate doses. In CER experiments, analogous selection intensities were applied to subsequent generations by increasing glyphosate doses. Conversely, in the field experiments, surviving plants were selected at a fixed glyphosate dose (Table 1). The effective population size $\left(N_{e}\right)$ was calculated as suggested by Falconer (1981) at each generation (Table 1). For a $t$ number of generations, the effective population size $\left(N_{e}\right)$ is given by the harmonic mean of the number of plants selected $\left(N_{i}\right)$ :

$$
\frac{1}{N_{e}}=\frac{1}{t} \sum_{i=1}^{t} \frac{1}{N_{i}}
$$

At flowering, the selected surviving plants were encaged in a pollen-proof enclosure to ensure random crosspollination (panmixia). The seed obtained from these selected plants represented the selected progeny. In CER selection experiments, the harvested seeds were maintained for at least 3 weeks in a warm $\left(37^{\circ} \mathrm{C}\right)$ and dry environment to release seed dormancy before the next cycle of selection was initiated. Seed germination rates greater than $60 \%$ were always achievable, and two consecutive cycles of selection per year were conducted. At each cycle of selection, the selected progeny was immediately evaluated and compared in dose-response studies to the unselected VLR1 population. The selection process was repeated four times, as previously described. Field selection experiments necessarily involved only one generation per year and were conducted for three consecutive growing seasons (3 years); then, all the 
Table 1 Seed progeny collected from a number of selected plants $\left(N_{i}\right)$ surviving a specific sublethal glyphosate dose $\left(\mathrm{g} \mathrm{Ha}{ }^{-1}\right)$ resulting in average selection intensity

\begin{tabular}{|c|c|c|c|c|c|}
\hline Progeny & Environment & $\begin{array}{l}\text { Glyphosate dose } \\
\qquad\left(\mathrm{gHa}^{-1}\right)\end{array}$ & $\begin{array}{l}\text { Selection intensity } \\
\text { (1-survival ratio) }\end{array}$ & $\begin{array}{l}\text { Plants selected } \\
\qquad\left(N_{i}\right)^{\mathrm{a}}\end{array}$ & $\begin{array}{c}\text { Effective population } \\
\text { size }\left(N_{e}\right)\end{array}$ \\
\hline $1 \mathrm{a}$ & CER & 150 & 0.71 & 32 & 32 \\
\hline $1 \mathrm{~b}$ & Field & 150 & 0.57 & 176 & 176 \\
\hline $1 \mathrm{c}$ & Field & 250 & 0.82 & 124 & 124 \\
\hline $1 d$ & Field & 350 & 0.92 & 44 & 44 \\
\hline $2 a$ & CER & 250 & 0.88 & 13 & 18 \\
\hline $2 b$ & Field & 150 & 0.33 & 22 & 39 \\
\hline $2 c$ & Field & 250 & 0.76 & 23 & 39 \\
\hline $2 d$ & Field & 350 & 0.83 & 23 & 30 \\
\hline $3 a$ & CER & 250 & 0.87 & 15 & 17 \\
\hline $3 b$ & Field & 150 & 0.30 & 20 & 30 \\
\hline $3 c$ & Field & 250 & 0.66 & 20 & 30 \\
\hline $3 d$ & Field & 350 & 0.82 & 20 & 26 \\
\hline $4 a$ & CER & 350 & 0.90 & 7 & 13 \\
\hline
\end{tabular}

Abbreviation: CER, controlled environment room.

The effective size of the population $\left(N_{e}\right)$ is calculated for each cycle of selection.

aplants grown to maturity that effectively produced seed after herbicide selection.

selected progenies were evaluated in final dose-response bioassays.

\section{Statistics applied to dose-response studies}

Data sets from repeated experiments were pooled, fitted to a non-linear logistic model and analyzed by a lack-offit $F$-test. If differences between repeated experiments were not significant, pooled data were used for subsequent non-linear regression analysis. Analysis of variance (ANOVA) and regression assumptions were held under square root data transformation (that is, Box-Cox transformation lambda, $\lambda=0.5$ ) (Box and Cox, 1964). The herbicide doses causing $50 \%$ plant mortality $\left(\mathrm{LD}_{50}\right)$ or growth reduction $\left(\mathrm{GR}_{50}\right)$ in the selected and unselected populations at each generation were estimated by using the logistic model:

$$
Y=c+\left[(d-c) /\left[1+(x / G)^{\mathrm{b}}\right]\right.
$$

$Y$ denotes plant survival or biomass expressed as a percentage of the untreated control, $d$ and $c$ are upper and lower asymptotic values of $Y$, respectively, $b$ the slope of the curve, $G$ the herbicide dose at the point of inflection halfway between the upper and the lower asymptotes, and $x$ the herbicide dose (Streibig et al., 1993). The response to selection for the different selected progenies was measured as the R/S (resistant/ susceptible) ratio of estimated $L_{50}$ or $\mathrm{GR}_{50}$ values. Mortality dose-response graphs are presented with untransformed data.

\section{Results}

\section{Response of the susceptible population VLR1 to glyphosate}

As expected, the unselected VLR1 population was confirmed to be susceptible to glyphosate. For CERgrown plants, only $2 \%$ of individuals survived $450 \mathrm{gHa}^{-1}$ glyphosate (that is, the recommended label rate in Australia) in several different dose-response studies (96 and $100 \%$ mortality at 350 and $550 \mathrm{~g} \mathrm{Ha}^{-1}$, respectively). Similarly, for plants grown in field conditions 93, 98, and $99 \%$ mortality was observed at 350, 450 and $550 \mathrm{~g} \mathrm{Ha}^{-1}$ glyphosate, respectively. However, as expected, there were survivors (phenotypic variation) at lower glyphosate doses (Figures 1 and 2). Glyphosate susceptibility (pooled data from several experiments) of plants grown in the CER vs the field environment was not significantly different $(P=0.381)$, with calculated $\mathrm{LD}_{50}$ values of 123 and $129 \mathrm{~g} \mathrm{Ha}^{-1}$, respectively.

\section{Response to recurrent selection with glyphosate sublethal doses \\ Glyphosate selection of CER-grown plants: Glyphosate} dose-response bioassays compared the glyphosateselected progeny 1a and 2a to the unselected originator population (VLR1). The $\mathrm{LD}_{50} \mathrm{R} / \mathrm{S}$ ratio showed a shift of $11 \%$ toward resistance in one generation, followed by a further $9 \%$ in the second generation. In progeny $2 a$, the resistance level continued to increase, and the estimated $\mathrm{LD}_{50}$ values obtained were higher than those obtained with progeny 1a (data not shown). An effective population size of 18 individuals (Table 1) after two selection cycles retained substantial genetic variation, because a significant additional shift toward glyphosate resistance occurred between the second and third selected progeny (Table 2). After three cycles of recurrent selection, progeny 3a clearly showed a level of glyphosate resistance: there was $20 \pm 1.7 \%$ survival at the registered glyphosate use rate of $450 \mathrm{~g} \mathrm{Ha}^{-1}$ (Figure 1a). The dose-response studies to quantify the level of glyphosate resistance in progeny 3a were repeated three times and the $L_{50} \mathrm{R} / \mathrm{S}$ ratios obtained ranged from 1.67 to 2.08 (Table 2). This resistance was also evident in the biomass measurements of these plants (Table 3 and Supplementary Figure S2). The level of resistance observed in progeny $3 a$ was confirmed in progeny 4a (Figure 1b). Similarly, the dose-response studies were repeated three times. In two experiments 
a

b

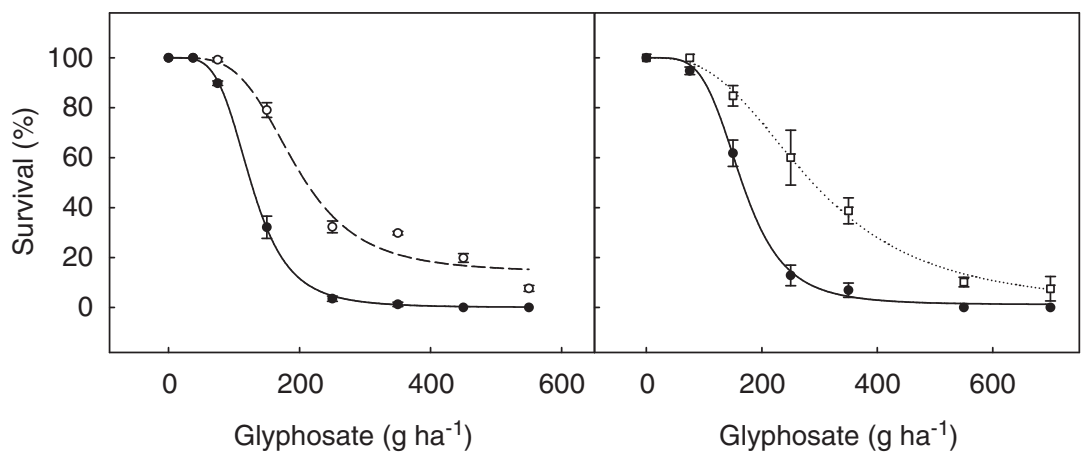

Figure 1 Glyphosate dose-response curves (survival) of glyphosate-selected progenies in CER. Solid circles and solid line represent the unselected original population (VLR1); (a) Open circles and dashed line, the three-time glyphosate-selected progeny 3a; (b) Open squares and dotted line, the four-time glyphosate-selected progeny 4 a. Symbols are mean \pm 1 s.e., $n=3$, lines are predicted values for percentage survival.

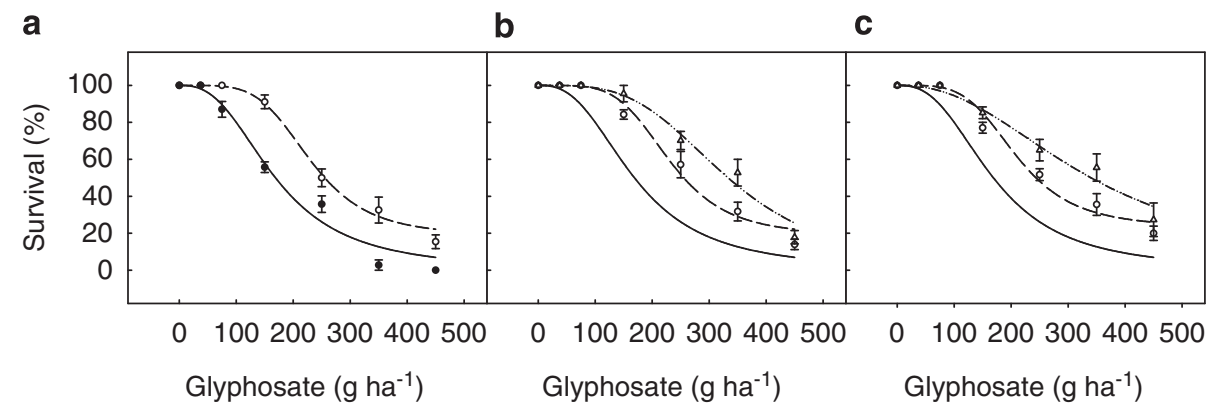

Figure 2 Glyphosate dose-response curves (survival) of glyphosate-selected progenies in field conditions. Solid circles and solid lines represent the unselected original population (VLR1); Open circles and dashed lines are the once glyphosate-selected progenies, open triangles and dash-dotted lines the twice glyphosate-selected progenies. (a) Once-selected progeny at $150 \mathrm{~g}_{\text {glyphosate ha }}{ }^{-1}$ (progeny $1 \mathrm{~b}$, refer to Table 1); (b) Once- and twice-selected progeny at $250 \mathrm{~g}$ glyphosate ha ${ }^{-1}$ (progeny 1c, 2c); (c) Once- and twice-selected progeny at $350 \mathrm{~g}$ glyphosate ha ${ }^{-1}$ (progeny $1 \mathrm{~d}, 2 \mathrm{~d}$ ). Symbols are mean \pm 1 s.e., $n=3$, lines are predicted values for percentage survival.

Table 2 Parameters of the log-logistic model $\left[Y=c+(d-c) /\left(1+(x / G)^{\mathrm{b}}\right)\right]$ used to calculate the $\mathrm{LD}_{50}$ values of selected and unselected progeny and their R/S ratios from dose-response studies (CER)

\begin{tabular}{lcccccrrr}
\hline Progeny & Experiments & $d$ & $c$ & $G$ & $b$ & $R M S^{\mathrm{a}}$ & $L D_{50}\left(g H a^{-1}\right)$ & $R / S$ \\
\hline VLR1 & $1-2$ & 100 & 0 & 126 & 4 & 25 & 126 \\
3a & $1-2$ & 100 & 14 & 194 & 4 & 41 & 210 \\
VLR1 & 3 & 100 & 0 & 77 & 3 & 2 & 76.6 \\
3a & 3 & 100 & 0 & 158 & 3 & 24 & 1.67 \\
VLR1 & $1-2$ & 100 & 1 & 165 & 5 & 62 & 165 \\
4a & $1-2$ & 100 & 0 & 288 & 3 & 166 & 2.08 \\
VLR1 & 3 & 100 & 2 & 121 & 3 & 188 & 1.73 \\
4a & 3 & 100 & 0 & 291 & 2 & 148 & 283 \\
\hline
\end{tabular}

ANOVA analysis conducted for each non-linear regression is highly significant $(P<0.001)$ and adjusted- $R^{2}>0.84$.

${ }^{\text {a }}$ Residual mean square.

(pooled data for analysis), the $\mathrm{LD}_{50}$ values for both the selected and unselected populations were higher than in the preceding bioassays. However, a consistent difference was maintained between the unselected population and glyphosate-selected progeny $4 a$. The highest $R / S$ value was obtained in the third repetition of the herbicide bioassay (Table 2). At the substantial dose of $550 \mathrm{~g} \mathrm{Ha}^{-1}$ glyphosate, the observed plant survival was $12 \pm 2.7$. Consistent results were obtained by assessing fresh and dry biomass to evaluate plant growth reduction in progeny 4 a (Table 3). It is important to note that, when grown to maturity, the glyphosate- selected survivors (progeny 4a) produced tillers and subsequent viable seed, whereas those VLR1 plants surviving the same glyphosate dose produced fewer tillers and significantly less seed (Supplementary Figure S1). Due to the recurrent selection acting on a small number of individuals, the effective size of the population in the selected progeny $4 \mathrm{a}$ was low (Table 1). However, no significant reduction was observed in plant biomass of untreated check plants. Pooled data from the three bioassays carried out on progeny 4a showed no significant difference in either fresh or dry plant weights $(P \geqslant 0.407)$ between the 
Table 3 Parameters of the log-logistic model $\left[Y=c+(d-c) /\left(1+(x / G)^{b}\right)\right]$ used to calculate the $\mathrm{GR}_{50}$ values of selected and unselected progeny and their R/S ratios from dose-response studies (CER)

\begin{tabular}{|c|c|c|c|c|c|c|c|c|}
\hline Progeny & Experiments & $d$ & $c$ & G & $b$ & $R M S^{\mathrm{a}}$ & $G R_{50}\left(g \mathrm{Ha}^{-1}\right)$ & $R / S$ \\
\hline VLR1 & $1-2$ & 100 & 2 & 82 & 3 & 38 & 82.9 & - \\
\hline $3 a$ & $1-2$ & 100 & 8 & 150 & 5 & 217 & 155 & 1.87 \\
\hline VLR1 & 3 & 100 & 7 & 31 & 2 & 9 & 33.6 & - \\
\hline $3 a$ & 3 & 100 & 8 & 72 & 2 & 197 & 77.6 & 2.31 \\
\hline VLR1 & $1-2$ & 100 & 7 & 78 & 4 & 81 & 80.8 & - \\
\hline $4 a$ & $1-2$ & 100 & 14 & 125 & 3 & 137 & 139 & 1.72 \\
\hline VLR1 & 3 & 100 & 4 & 67 & 3 & 35 & 68.9 & - \\
\hline $4 a$ & 3 & 100 & 0 & 116 & 2 & 124 & 116 & 1.68 \\
\hline
\end{tabular}

ANOVA analysis conducted for each non-linear regression is highly significant $(P<0.001)$ adjusted- $R^{2}>0.89$.

${ }^{a}$ Residual mean square.

Table 4 Parameters of the $\log$-logistic model $\left[Y=c+(d-c) /\left(1+(x / G)^{\mathrm{b}}\right)\right]$ used to calculate the $\mathrm{LD}_{50}$ values of selected and unselected progeny, and their R/S ratios from dose-response studies (Field)

\begin{tabular}{|c|c|c|c|c|c|c|c|}
\hline Population & $d$ & $c$ & $G$ & $b$ & $R M S^{\mathrm{a}}$ & $L D_{50}\left(g \mathrm{Ha}^{-1}\right)$ & $R / S$ \\
\hline VLR1 & 100 & 0 & 169 & 3 & 92 & 169 & - \\
\hline $1 b$ & 100 & 18 & 231 & 5 & 50 & 255 & 1.51 \\
\hline $3 b$ & 100 & 27 & 226 & 5 & 28 & 268 & 1.59 \\
\hline 1c & 100 & 0 & 269 & 3 & 40 & 269 & 1.59 \\
\hline $2 c$ & 100 & 0 & 333 & 4 & 71 & 333 & 1.97 \\
\hline $3 c$ & 100 & 0 & 325 & 3 & 137 & 325 & 1.92 \\
\hline $1 \mathrm{~d}$ & 100 & 1 & 257 & 2 & 37 & 260 & 1.54 \\
\hline $2 d$ & 100 & 0 & 340 & 2 & 84 & 340 & 2.01 \\
\hline $3 d$ & 100 & 31 & 237 & 3 & 80 & 315 & 1.87 \\
\hline
\end{tabular}

ANOVA analysis conducted for each non-linear regression is highly significant $(P<0.001)$ and adjusted- $R^{2}>0.83$.

${ }^{\mathrm{a}}$ Residual mean square.

Table 5 Parameters of the $\log$-logistic model $\left[Y=c+(d-c) /\left(1+(x / G)^{\mathrm{b}}\right)\right]$ used to calculate the $\mathrm{GR}_{50}$ of selected and unselected progeny and their $\mathrm{R} / \mathrm{S}$ ratios from dose-response studies (Field)

\begin{tabular}{|c|c|c|c|c|c|c|c|c|}
\hline Population & $f^{a}$ & $d$ & $c$ & G & $b$ & $R M S^{\mathrm{b}}$ & $G R_{50}\left(g H a^{-1}\right)$ & $R / S$ \\
\hline VLR1 & 1 & 100 & -12 & 71 & 2 & 113 & 133 & - \\
\hline $1 b$ & 0 & 99 & 7 & 172 & 5 & 72 & 179 & 1.35 \\
\hline $3 b$ & 12 & 100 & -40 & 28 & 2 & 238 & 252 & 1.90 \\
\hline $1 c$ & 4 & 100 & -243 & 78 & 1 & 114 & 133 & 1.00 \\
\hline $2 c$ & 4 & 100 & -88 & 77 & 2 & 560 & 241 & 1.82 \\
\hline $3 c$ & 0 & 98 & 12 & 154 & 3 & 155 & 214 & 1.62 \\
\hline $1 d$ & 1 & 100 & 11 & 95 & 3 & 139 & 152 & 1.15 \\
\hline $2 d$ & 9 & 100 & -104 & 30 & 1 & 173 & 170 & 1.28 \\
\hline $3 d$ & 1 & 100 & 14 & 126 & 4 & 287 & 193 & 1.45 \\
\hline
\end{tabular}

ANOVA analysis conducted for each non-linear regression is highly significant $(P<0.001)$ and adjusted- $R^{2}>0.87$.

${ }^{a}$ Where A stimulation of plant growth at low doses (hormesis) was observed this log-logistic model was used $Y=c+\left[(d-c)+\left(f^{*} x\right)\right] /\left[\left(1+(x / G)^{b}\right)\right]$ In the equation, $f$ is proportional to the hormetic behavior.

${ }^{\mathrm{b}}$ Residual mean square.

selected progeny $4 \mathrm{a}$ and the unselected VLR1 population.

Glyphosate selection of field-grown plants: Glyphosate dose-response studies were conducted to compare the one-, two- and three-time glyphosate-selected progenies vs the unselected originator population (VLR1). It is emphasized that in this final experiment, all plants were grown in the same field environment at the same time. The once-selected progenies showed higher survival to glyphosate compared with unselected VLR1 (Table 4, Figures 2a-c). An increased level of resistance was observed in the three-time selected populations, but no further incremental shift toward glyphosate resistance was observed in the thrice-selected progenies. The maximum resistance levels were observed in populations $2 \mathrm{c}$ and $2 \mathrm{~d}$, twice-selected at the highest doses (250 and $350 \mathrm{~g} \mathrm{Ha}^{-1}$ glyphosate, respectively) (Tables 4 and 5, Figures 2a-c and Supplementary Figure S3). Up to $33 \% \pm 4.3$ plant survival was obtained in the progeny $3 \mathrm{~d}$ at the recommended field rate of $450 \mathrm{~g} \mathrm{Ha}^{-1}$.

\section{Discussion}

\section{Effect of recurrent selection at sublethal doses of glyphosate}

Herbicide resistance is the evolved and inherited capacity of a plant population to withstand the normal recommended herbicide dose (registered label rate) that 
had been previously effective in controlling the same population (Hall et al., 1994). Here, we show that with an initially glyphosate-susceptible L. rigidum population, three to four generations of recurrent selection at sublethal glyphosate doses (in two different environments) are sufficient to cause a shift toward glyphosate resistance (Tables 2-5, Figures 1 and 2, Photo Supplementary Figure S1). It is emphasized that this recurrent glyphosate selection study commenced with a population (VLR1) highly characterized as susceptible to a wide range of herbicides, including glyphosate (Yu et al., 2007). The results we obtained with glyphosate selection are similar to earlier experiments in which the same L. rigidum population evolved resistance from recurrent selection at sublethal doses of diclofop-methyl (Neve and Powles, 2005b). In a field-evolved glyphosate-resistant population of L. rigidum the contribution of complementary minor genes for glyphosate resistance at a low glyphosate rate $\left(225 \mathrm{~g} \mathrm{Ha}^{-1}\right)$ could not be excluded because of higher-than-expected survival in back-cross families (Lorraine-Colwill et al., 2001). The glyphosateselected progenies reported here showed a progressive increase in survival after each generation of recurrent glyphosate selection, suggesting the involvement and progressive accumulation of minor gene trait(s). However, the genetic basis remains to be determined. Preliminary analysis by using the polygenic platform qugene (Podlich and Cooper, 1998), under a simplified range of genetic assumptions suggests the potential involvement of one or two minor additive genes (Supplementary Figure S4b, c, f, g).

The selected glyphosate resistance was consistent under different environmental conditions (CER vs field) and at different stages of plant development illustrating the potential for a herbicide-resistant population to be selected by the use of sublethal herbicide doses in variable field conditions (Supplementary Table S1). The level of resistance to glyphosate after three or four generations of recurrent selection at sublethal glyphosate doses (Figures 1 and 2) was much lower than the level of diclofop-methyl resistance evident after three cycles of recurrent selection with diclofop-methyl (Neve and Powles, 2005b). Glyphosate resistance from recurrent selection at a sublethal glyphosate dose is moderate when compared with $\mathrm{LD}_{50}$ values obtained in fieldevolved glyphosate-resistant populations of L. rigidum (Powles et al., 1998; Yu et al., 2007) or glyphosate-resistant biotypes in other species (reviewed in Gustafson, 2008; Vila-Aiub et al., 2008).

It is clear that for glyphosate, the phenotypic variation in glyphosate sensitivity displayed in even a small number of individuals is sufficient and when exposed to recurrent selection at sublethal glyphosate doses, this can result in a shift toward resistance within a few generations. However, the magnitude and the rate of these evolutionary phenomena are dependent on the specifics of the herbicide molecule, the biology of the plant species and any potential resistance mechanisms present in the population under selection. Allogamous (obligate cross-pollinated) species such as Lolium are particularly responsive because all existing minor resistance gene trait(s) may be additively enriched through cross-pollination among surviving plants. This does not occur in self-pollinated species or it may be a much slower evolution depending on the out-crossing rate
(Holsinger, 2000). For example, no shift in glyphosate resistance has been observed in a susceptible population of self-pollinated Avena fatua subjected to recurrent lowdose glyphosate selection ( $R$ Busi and SB Powles, unpublished). Similarly, the visual inspection of glyphosate-treated seedlings failed to identify a shift toward glyphosate resistance in self-pollinated Arabidopsis thaliana L. after seven cycles of recurrent selection at low doses of glyphosate (Brotherton et al., 2007). Therefore, we conclude that cross-pollination is a significant factor in herbicide resistance evolution from recurrent selection, as crosspollination enables the progressive accumulation of minor genes (Neve and Powles, 2005a, b).

\section{Population size and evolution of herbicide resistance after recurrent selection}

The genus Lolium is genetically variable (Balfourier et al., 1998), and a small population subjected to a severe bottleneck still retains genetic variation (Cooper, 1959). Substantial herbicide resistance evolution occurred in both this experiment and the selection study reported by Neve and Powles (2005b). In this study, a sufficient number of surviving plants at each generation ensured that adequate population size and genetic variation were maintained throughout the course of the recurrent selection (Polans and Allard, 1989) (Table 1). Probably, there was a constant level of heritability at each cycle of recurrent selection, due to similar environmental conditions obtained in both CER and the field environment. However, there was only a small or negligible increment in $R / S$ ratios obtained with three- (field) or four-time (CER) glyphosate-selected progenies. This phenomenon, together with a declining effective population size (Table 1) because of a progressive genetic bottleneck imposed by recurrent selection, suggests that the shift in glyphosate resistance achieved in three or four generations may correspond to the maximum level achievable (Falconer, 1981). However, no substantial effects of genetic stress by restricting the population size were observed on the biomass of untreated plants (comparing unselected VLR1 and selected populations). We conclude that the variable phenotypic responses evident at sublethal herbicide doses means that even in a small susceptible L. rigidum population, these minor gene trait(s) can be enriched and channeled by recurrent selection to result in a degree of herbicide resistance (Neve and Powles, 2005a, b).

\section{Potential mechanistic basis for low-dose-selected glyphosate resistance}

In field-evolved glyphosate-resistant weed biotypes, two distinct glyphosate resistance mechanisms have been identified (reviewed by Powles and Preston, 2006). In $L$. rigidum, a reduced glyphosate translocation resistance mechanism and a mutation in the EPSPS target gene have been documented (Yu et al., 2007; Preston and Wakelin, 2008). These two mechanisms are each single gene traits (Powles and Preston, 2006; Wakelin and Preston, 2006a, 2006b). It is very unlikely that these rare single genes were present in our originator susceptible population VLR1, given the very small number of plants that we had exposed to glyphosate selection ( $\mathrm{Yu}$ et al., 2007). Aside from these two single-gene-endowed glyphosate resistance mechan- 
isms, reduced foliar retention of glyphosate and differential uptake have also been reported in Lolium (Michitte et al., 2007). In our low-dose glyphosate-selected population, the mechanistic basis of resistance remains to be identified. We presume it may be multi-faceted because a gradual enrichment and accumulation of minor gene trait(s) was observed.

\section{Conclusions}

Identifying the main factors influencing the evolution of resistant weed populations is crucial for understanding, predicting and managing herbicide resistance. Our study highlights that selection at low (sublethal) glyphosate doses in cross-pollinated, genetically variable Lolium can lead to glyphosate resistance evolution. The results presented here are of special significance because of the importance of glyphosate in world food production and the recent evolution of several glyphosate-resistant weed biotypes (Powles, 2008). Moreover, these data might be relevant to the continued evolution of herbicide resistance crop technology toward the development of new breeding stacks for multiple herbicide-resistant crops combining resistance to several modes of action. We believe that herbicides should be used at the recommended rate to achieve high weed mortality and therefore minimize the possibility of accumulation of minor gene traits (creeping resistance) that may endow a level of resistance over a few generations. The rapid evolution of glyphosate (Figure 2) and diclofop-methyl resistance (Neve and Powles, 2005b) due to the recurrent use of low (sublethal) herbicide doses warrants future research on other herbicide modes of action. The genetic control and resistance mechanisms enriched from a susceptible small population remain unknown and should be investigated to identify the basis of lowdose-selected resistance. Substantial precautions need to be taken by the industry to ensure that herbicides are used at the registered recommended rates. This should contribute to the sustainability and longevity of herbicide molecules in world agriculture.

\section{Acknowledgements}

We are grateful to Drs D Goggin, Q Yu and M Vila-Aiub for critically reading the paper. The Western Australian Herbicide Research Initiative (WAHRI) is funded by the Grains Research and Development Corporation of Australia (GRDC).

\section{References}

Balfourier F, Charmet G, Ravel C (1998). Genetic differentiation within and between natural populations of perennial and annual ryegrass (Lolium perenne and L. rigidum). Heredity 81: 100-110.

Box GEP, Cox DR (1964). An analysis of transformations. $J$ R Stat Soc, Series B 26: 211-243.

Brotherton JE, Jeschke MR, Tranel PJ, Widholm JM (2007). Identification of Arabidopsis thaliana variants with differential glyphosate responses. J Plant Physiol 164: 1337-1345.

Cooper JP (1959). Selection and population structure in Lolium. III. Selection for date of ear emergence. Heredity 13: 461-479.

Darmency H (1994). Genetics of herbicide resistance in weeds and crops. In: Powles SB, Holtum JAM (eds). Herbicide
Resistance in Plants: Biology and Biochemistry. Lewis Publishers: Boca Raton. pp 263-297.

Dill MD, Cajacob CA, Padgette SR (2008). Glyphosate-resistant crops: adoption, use and future considerations. Pest Manag Sci 64: 326-331.

Duke SO, Powles SB (2008). Glyphosate: a once in a century herbicide. Pest Manag Sci 64: 319-325.

Falconer DS (1981). Introduction to Quantitative Genetics, 2nd edn. Longman: London, UK. 65pp.

Gaines T (2009). Molecular Genetics of glyphosate resistance in palmer amaranth (Amaranthus palmeri L.). PhD Thesis dissertation. Colorado State University, Fort Collins, CO, USA.

Gressel J (1995). Creeping resistances: the outcome of using marginally effective or reduced rates of herbicides. Brighton Crop Protection Conference-Weeds. British Crop Protection Council Publications: Brighton. pp 587-590.

Gressel J (2002). Molecular Biology of Weed Control. Taylor and Francis: London. 520pp.

Gustafson DI (2008). Sustainable use of glyphosate in North American cropping systems. Pest Manag Sci 64: 409-416.

Hall LM, Holtum JAM, Powles SB (1994). Mechanisms responsible for cross resistance and multiple resistance. In: Powles SB and Holtum JAM (eds). Herbicide Resistance in Plants: Biology and Biochemistry. Lewis Publisher, Boca Raton, FL. pp 243-261.

Holsinger K (2000). Reproductive systems and evolution in vascular plants. Proc Natl Acad Sci USA 97: 7037-7042.

Jasieniuk M, BruleBabel AL, Morrison IN (1996). The evolution and genetics of herbicide resistance in weeds. Weed Sci 44: 176-193.

Lorraine-Colwill DF, Powles SB, Hawkes TR, Preston C (2001). Inheritance of evolved glyphosate resistance in Lolium rigidum (Gaud.). Theoret Appl Genet 102: 545-550.

Michitte P, De Prado R, Espinoza N, Ruiz-Santaella JP, Gauvrit C (2007). Mechanisms of resistance to glyphosate in a Ryegrass (Lolium multiflorum) biotype from Chile. Weed Sci 55: 435-440.

Neve P (2008). Simulation modelling to understand the evolution and management of glyphosate resistance in weeds. Pest Manag Sci 64: 392-401.

Neve P, Powles SB (2005a). High survival frequencies at low herbicide use rates in populations of Lolium rigidum result in rapid evolution of herbicide resistance. Heredity 95: 485-492.

Neve P, Powles SB (2005b). Recurrent selection with reduced herbicide rates results in the rapid evolution of herbicide resistance in Lolium rigidum. Theoret Appl Genet 110: 1154-1166.

$\mathrm{Ng} \mathrm{CH}$, Ratnam W, Surif S, Ismail BS (2004). Inheritance of glyphosate resistance in goosegrass (Eleusine indica). Weed Sci 52: 564-570.

O'Donovan JT, Blackshaw RE, Harker KN, Clayton GW, Moyer JR, Dosdall LM et al. (2007). Integrated approaches to managing weeds in spring-sown crops in western Canada. Crop Protection 26: 390-398.

Olofsson SK, Cars O (2007). Optimizing drug exposure to minimize selection of antibiotic resistance. Clin Infect Dis 45 (S): 129-136.

Owen MDK (2008). Weed species shifts in glyphosate resistant crops. Pest Manag Sci 64: 377-387.

Podlich D, Cooper M (1998). QU-GENE: a simulation platform for quantitative analysis of genetic models. Bioinformatics 14: 632-653.

Polans NE, Allard RW (1989). An experimental evaluation of the recovery potential of ryegrass populations from genetic stress resulting from restriction of population size. Evolution 43: 1320-1324.

Powles SB (2008). Evolved glyphosate resistant weeds around the world: lessons to be learnt. Pest Manag Sci 64: 360-365.

Powles SB, Lorraine-Colwill DF, Dellow JJ, Preston C (1998). Evolved resistance to glyphosate in rigid ryegrass (Lolium rigidum) in Australia. Weed Sci 46: 604-607.

Powles SB, Preston C (2006). Evolved glyphosate resistance in plants: biochemical and genetic basis of resistance. Weed Technol 20: 282-289. 
Preston C, Powles SB (2002). Evolution of herbicide resistance in weeds: initial frequency of target site-based resistance to acetolactate synthase-inhibiting herbicides in Lolium rigidum. Heredity 88: 8-13.

Preston C, Wakelin AM (2008). Resistance to glyphosate from altered herbicide translocation patterns. Pest Manag Sci 64: 372-376.

Roush RT, McKenzie JA (1987). Ecological genetics of insecticide and acaricide resistance. Annu Rev Entomol 32: 361-380.

Shaw MW (2006). Is there such a thing as a fungicide resistance strategy? A modeller's perspective. Aspects Appl Biol 78: 37-44.

Streibig JC, Rudemo M, Jensen JE (1993). Dose-response curves and statistical models. In: Streibig PKE (ed). Herbicide Bioassays. CRC: Boca Raton, FL. pp 29-55.

Vila-Aiub MM, Vidal RA, Balbi MC, Gundel PE, Trucco F, Ghersa CM (2008). Glyphosate-resistant weeds of South
American cropping systems: an overview. Pest Manag Sci 64: 366-371.

Wakelin AM, Preston C (2006a). Inheritance of glyphosate resistance in several populations of rigid ryegrass (Lolium rigidum) from Australia. Weed Sci 54: 212-219.

Wakelin AM, Preston C (2006b). A target-site mutation is present in a glyphosate-resistant Lolium rigidum population. Weed Res 46: 432-440.

Yu Q, Cairns A, Powles S (2007). Glyphosate, paraquat and ACCase multiple herbicide resistance evolved in a Lolium rigidum biotype. Planta 225: 499-513.

Zelaya IA, Owen MDK, VanGessel MJ (2004). Inheritance of evolved glyphosate resistance in Conyza canadensis (L.) Cronq. Theoret Appl Genet 110: 58-70.

Zhang J, Weaver LM, Hamill AS (2000). Risks and reliability of using herbicides at below-labeled rates. Weed Technol 14: 106-115.

Supplementary Information accompanies the paper on Heredity website (http://www.nature.com/hdy) 